\title{
Branched Polymeric Media: Perchlorate-Selective Resins from Hyperbranched Polyethyleneimine
}

\author{
Dennis P. Chen, ${ }^{\dagger}$ Changjun Yu, ${ }^{\ddagger}$, Ching-Yu Chang, ${ }^{\ddagger}$ Yanjian Wan, ${ }^{\ddagger}$ Jean M. J. Frechet, ${ }^{\|, \perp}$
}

William A. Goddard, III, ${ }^{\#, \dagger}$ and Mamadou S. Diallo ${ }^{\dagger, \S, *}$

${ }^{\dagger}$ Graduate School of Energy, Environment, Water and Sustainability (EEWS), Korea Advanced Institute of Science and Technology (KAIST), Daejon, Republic of Korea

${ }^{\ddagger}$ AquaNano, LLC Monrovia, California, United States

${ }^{\S}$ Environmental Science and Engineering Division of Engineering and Applied Science, California Institute of Technology, Pasadena, California, United States

"Department of Chemistry, University of California, Berkeley, California, United States

${ }^{\perp}$ King Adullah University of Science and Technology, Thuwal, Saudi Arabia

${ }^{\#}$ Materials and Process Simulation Center Division of Chemistry and Chemical Engineering, California Institute of Technology, Pasadena, California, United States

\section{Supporting Information}

ABSTRACT: Perchlorate $\left(\mathrm{ClO}_{4}^{-}\right)$is a persistent contaminant found in drinking groundwater sources in the United States. Ion exchange (IX) with selective and disposable resins based on cross-linked styrene divinylbenzene (STY-DVB) beads is currently the most commonly utilized process for removing low concentrations of $\mathrm{ClO}_{4}^{-}(10-100 \mathrm{ppb})$ from contaminated drinking water sources. However, due to the low exchange capacity of perchlorate-selective STY-DVB resins ( $\sim 0.5-0.8 \mathrm{eq} / \mathrm{L})$, the overall cost becomes prohibitive when

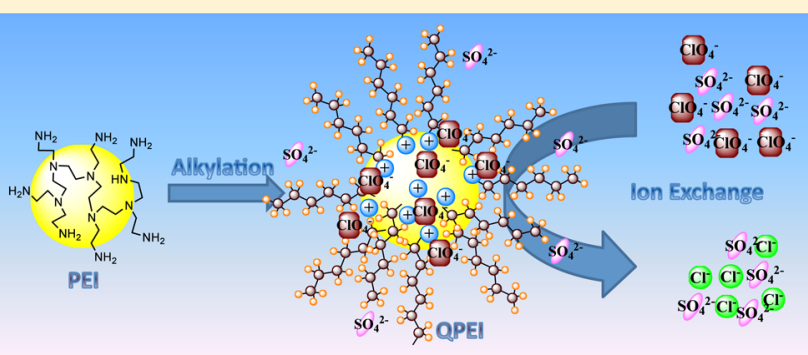
treating groundwater with higher concentration of $\mathrm{ClO}_{4}^{-}$(e.g., 100-1000 ppb). In this article, we describe a new perchlorate-selective resin with high exchange capacity. This new resin was prepared by alkylation of branched polyethyleneimine (PEI) beads obtained from an inverse suspension polymerization process. Batch and column studies show that our new PEI resin with mixed hexyl/ethyl quaternary ammonium chloride exchange sites can selectively extract trace amounts of $\mathrm{ClO}_{4}^{-}$from a makeup groundwater (to below detection limit) in the presence of competing ions. In addition, this resin has a strong-base exchange capacity of $1.4 \mathrm{eq} / \mathrm{L}$, which is $1.75-2.33$ times larger than those of commercial perchlorate-selective STY-DVB resins. The overall results of our studies suggest that branched PEI beads provide versatile and promising building blocks for the preparation of perchlorate-selective resins with high exchange capacity.

\section{INTRODUCTION}

Perchlorate $\left(\mathrm{ClO}_{4}^{-}\right)$is a water-soluble anion that has been widely used in the manufacturing of explosives, mines, and solid propellants for pyrotechnic devices, rockets, and missiles. ${ }^{1}$ It has emerged as a groundwater and surface water contaminant in 22 U.S. states since the development of a sensitive ion chromatography assay that can detect low levels of perchlorate in water, i.e. $2 \mu \mathrm{g} / \mathrm{L}(\mathrm{ppb}){ }^{1-3}$ When ingested at high concentrations, $\mathrm{ClO}_{4}^{-}$can inhibit the uptake of iodide by the thyroid gland and may disrupt its ability to produce hormones critical to developing fetuses and infants. Although the United States Environmental Agency (EPA) has yet to formally set a limit for the level of $\mathrm{ClO}_{4}{ }^{-}$in potable water, various states have set public health goals (PHG) for drinking water. For example, Massachusetts has established a PHG based on a maximum concentration limit (MCL) of $\mathrm{ClO}_{4}^{-}$of $2 \mathrm{ppb}$. Similarly, the State of California established an MCL of $6 \mathrm{ppb}$ in October 2007 and, in January 2011 and has proposed to reduce the
MCL for $\mathrm{ClO}_{4}{ }^{-}$in drinking water from 6 to $1 \mathrm{ppb}^{4}$ Reverse osmosis, nanofiltration and electrodialysis are not cost-effective for the treatment of drinking groundwater sources contaminated by low-concentrations of $\mathrm{ClO}_{4}^{-}(<100 \mathrm{ppb}) .^{5}$ Ion exchange (IX) using selective resins is currently the most widely used process for treating groundwater with low concentration of $\mathrm{ClO}_{4}{ }^{-}$, that is, less than $100 \mathrm{ppb}^{6-8}$ Today, anion-selective resins used to extract $\mathrm{ClO}_{4}{ }^{-}$from groundwater are exclusively prepared by functionalization of cross-linked styrene divinylbenzene (STY-DVB) beads. ${ }^{9-11}$ STY-DVB resins such as the commercial A-530E resin from Purolite can selectively and efficiently extract $\mathrm{ClO}_{4}{ }^{-}$from groundwater containing low amounts of perchlorate $(10-100 \mathrm{ppb})$ to below

Received: April 10, 2012

Revised: August 30, 2012

Accepted: September 5, 2012

Published: September 5, 2012 
the detection limit of $2 \mathrm{ppb}^{6-8}$ However, resins such as the A$530 \mathrm{E}$ resin have limited exchange capacities $(0.6 \mathrm{eq} / \mathrm{L})^{12}$ and cannot be efficiently regenerated by conventional brine elution. Because of this, perchlorate-selective media such as the A530-E resin are discarded after a single use once they become saturated with $\mathrm{ClO}_{4}^{-}$and as a result, the overall cost becomes prohibitive when treating groundwater with higher perchlorate concentrations (e.g., 100-1000 ppb). Thus, there is a critical need for new perchlorate-selective resins with high exchange capacity.

Most anion extraction processes by ion exchange in water treatment such as the removal of $\mathrm{ClO}_{4}^{-}$from drinking groundwater are carried out in columns or packed beds. ${ }^{6-9}$ In these applications, the strong-base volume exchange capacity $\left(\mathrm{SBEC}_{\mathrm{v}}\right)$-defined as the number of exchange sites (eq) per unit volume $(\mathrm{L})$ of fully swollen resin bed-is the critical measure of the resin capacity. ${ }^{9}$ Since the first reported synthesis of STY-DVB anion exchange resins, many attempts have been made to synthesize anion exchange resins with high $\mathrm{SBEC}_{\mathrm{v}}$ using polyamines such as branched polyethyleneimine (PEI) as precursors. ${ }^{9,13-19}$ However, none of these previous studies has reported anion exchange resins with $\mathrm{SBEC}_{\mathrm{v}}$ exceeding those of the commercial STY-DVB resins. In our efforts to develop high capacity and selective resins for $\mathrm{ClO}_{4}^{-}$removal, we report a perchlorate-selective resin with high $\mathrm{SBEC}_{\mathrm{v}}$. This resin was prepared by alkylation of branched polyethyleneimine (PEI) resins obtained from an inverse suspension process. Batch and column studies show that our new PEI resin with mixed hexyl/ ethyl quaternary ammonium chloride exchange sites can selectively extract trace amounts of $\mathrm{ClO}_{4}{ }^{-}$(to below detection limit) from a makeup groundwater in the presence of competing ions. In addition, our new perchlorate-selective resin has a strong-base exchange capacity of $1.4 \mathrm{eq} / \mathrm{L}$, which is 2.3 times higher than that of the commercial A530-E resin. This perchlorate-selective STY-DVB resin has a $\mathrm{SBEC}_{\mathrm{v}}$ of $0.6 \mathrm{eq} /$ L. ${ }^{12}$ The overall results of our studies suggest that branched PEI beads provide versatile and promising building blocks for the preparation of perchlorate-selective resins with high exchange capacity.

\section{EXPERIMENTAL METHODS AND PROCEDURES}

Resin Synthesis. Reagent grade chemicals (>98 wt \%) were used to synthesize the PEI resin beads. Deionized (DI) water (minimum resistivity $18 \mathrm{M} \Omega$ ) was obtained from a Milli-Q filtration unit. Anhydrous sodium chloride $(\mathrm{NaCl})$, sodium perchlorate $\left(\mathrm{NaClO}_{4}\right)$, sodium bicarbonate $\left(\mathrm{NaHCO}_{3}\right)$, sodium nitrate $\left(\mathrm{NaNO}_{3}\right)$ and sodium sulfate $\left(\mathrm{Na}_{2} \mathrm{SO}_{4}\right)$ were purchased from Alfa Aesar. Concentrated hydrochloric acid (12 $\mathrm{N})$ was purchased from EMD. Branched polyethyleneimine (PEI) [SP-200 with molar mass $M_{\mathrm{n}}=10,000 \mathrm{Da}$ and SP-018 with $\left.M_{\mathrm{n}}=1800 \mathrm{Da}\right]$ was purchased from Nippon Shokubai Co., Ltd. Sulfonic 100 (branched dodecyl benzene sulfonic acid, 97\%) was purchased from the Stepan Company. Bromoethane, iodomethane, 1-bromopropane, 1-bromo-2-methylpropane, 1bromobutane, 1-bromo-3-chloropropane (BCP), diisopropylethylamine and epichlorohydrin $(\mathrm{ECH})$ were purchased from Sigma-Aldrich. Methanol ( $\mathrm{MeOH})$, ethanol (EtOH), toluene, isopropanol, and sodium hydroxide $(\mathrm{NaOH})$ were purchased from Mallinckrodt Chemicals. All chemicals were used as received. All base PEI resins were synthesized using an inverse suspension of water-in-toluene stabilized by a surfactant as recently described by Diallo and co-workers. ${ }^{20}$ The PEI resins were subsequently reacted with alkylating reagents to produce resins with quaternary ammonium chloride $\left(\mathrm{Cl}^{-}\right)$exchange sites and tunable perchlorate-selectivity. Section 1 of the Supporting Information (SI) provides a detailed description of the resin synthesis procedures.

Commercial Resins. We utilized three commercial resins to benchmark the performance of our new perchlorate-selective resins. Samples of the A-850 and A-530E resins were provided by The Purolite Company (Bala Cynwyd, PA). The commercial DOWEX 1 resin was purchased from The Dow Chemical Company (Midland, MI).

Resin Characterization. The physicochemical properties of the PEI resins were characterized using a broad range of analytical assays/tools including (i) FT-IR spectroscopy, (ii) SEM imaging, (iii) particle size distribution (PSD) analysis, and (iv) water content and exchange capacity measurements. The FT-IR spectra of selected PEI resins were acquired using a Bruker VERTEX 70/70v FT-IR spectrometer with KBR pellets and OPUS software for data processing. All the reported IR spectra represent averages of more than 100 consecutive scans. The SEM images were acquired using a JEOL JEM-2100F microscope. Prior to imaging, each sample was mounted on a stage covered with carbon tape and sputter-coated with platinum. A Malvern Mastersizer 2000 was employed to analyze the PSD of the perchlorate-selective PEI resins.

The water content of each resin was measured by drying 2-3 $\mathrm{g}$ of moist resin under reduced pressure until the weight remained constant. Prior to testing, all resins were loaded in a glass column $(5.1 \mathrm{~cm}$ i.d. $\times 20.3 \mathrm{~cm}$ in length $)$ and washed successively with methanol $(1 \mathrm{~L} / 10 \mathrm{~g}$ of resin), deionized (DI) water $(1 \mathrm{~L} / 10 \mathrm{~g}$ of resin), $5.0 \mathrm{wt} \% \mathrm{NaCl}(1 \mathrm{~L} / 10 \mathrm{~g}$ of resin), and again with DI water $(1 \mathrm{~L} / 10 \mathrm{~g}$ of resin). Following the wash, the resins were partially dried at room temperature. The strong-base volume exchange capacity $\left(\mathrm{SBEC}_{\mathrm{v}}\right)$ of each resin was measured by Mohr titration using the standard procedure ASTM-D2187 (2009). ${ }^{21}$ In a typical experiment, $4 \mathrm{~g}$ of resin was mixed with $10 \mathrm{~mL}$ of DI water. The resin slurry was packed in a graduated cylinder and allowed to equilibrate for overnight. The bed volume (BV) of the resin was then measured. Subsequently, the resin slurry was packed in a fritted glass column and saturated with a solution of sodium chloride $(\mathrm{NaCl})[5.0 \mathrm{wt} \%]$ to obtain its chloride form. The column was then washed with $1 \mathrm{~L}$ of DI water to remove excess chloride in the solution. The remaining chloride ions were eluted out with a $1 \mathrm{~L}$ solution of sodium nitrate $\left(\mathrm{NaNO}_{3}\right)[2.0 \mathrm{wt} \%]$ and collected in a volumetric flask. Following this, the concentration of chloride in the effluent was measured by titrating an aliquot of $100 \mathrm{~mL}$ effluent solution with a solution of silver nitrate $\left(\mathrm{AgNO}_{3}\right)$. The strong base capacity $(\mathrm{meq} / \mathrm{mL})$ was expressed as follows:

$$
\mathrm{SBEC}_{\mathrm{v}}=V \times N \times \mathrm{DR} / \mathrm{BV}
$$

where $V(\mathrm{~mL})$ and $N(\mathrm{meq} / \mathrm{mL})$ are, respectively, the volume and normality of the silver nitrate solution, $\mathrm{BV}(\mathrm{mL})$ is the volume of the swollen resin and DR is the dilution ratio, which is equal to 10 in this case.

Batch Equilibrium Sorption Studies. Batch equilibrium sorption studies were carried out to evaluate the performance of the PEI resins against representative commercial resins. The $\mathrm{ClO}_{4}{ }^{-}$resin-water distribution coefficient $K_{\mathrm{d}}(\mathrm{mL} / \mathrm{g})$ was used as a measure of resin binding affinity for the batch studies. For the screening studies, we performed single point $K_{d}$ measurements. In this case, perchlorate sorption onto the resins was measured by mixing $50 \mathrm{mg}$ (dry weight equivalent) of media 
with $50 \mathrm{~mL}$ of a test solution containing $625 \mathrm{ppb}$ ofClO $_{4}^{-}$. For isotherm measurements in the linear sorption range, perchlorate sorption onto the resins was determined by mixing 50 mg (dry weight equivalent) of media with $50 \mathrm{~mL}$ of a test solution with $\mathrm{ClO}_{4}{ }^{-}$concentration ranging from 0.5 to $10 \mathrm{mg} /$ L. In both cases, the test solution was representative of a contaminated groundwater from Redlands (California) that was employed in a previous study of perchlorate-selective STY-DVB resins conducted by Oak Ridge National Laboratory. ${ }^{6}$ The makeup Redlands groundwater was prepared by dissolving 3 $\mathrm{mM}$ of $\mathrm{NaHCO}_{3}, 3 \mathrm{mM}$ of $\mathrm{NaCl}, 0.5 \mathrm{mM}$ of $\mathrm{Na}_{2} \mathrm{SO}_{4}$ and 0.5 $\mathrm{mM}$ of $\mathrm{NaNO}_{3}$ in deionized water. The initial and final concentrations of $\mathrm{ClO}_{4}^{-}$in solution were measured by ion chromatography (IC) using EPA method 314.0. ${ }^{3}$ The instrument consisted of a Dionex ICS-2000 ion chromatograph equipped with an electrolytic suppressor (CSRS-300 $4 \mathrm{~mm}$ ), a dual piston pump, a potassium hydroxide eluent generator cartridge (EGCIII), a heated conductivity cell, an AS40 auto sampler, an AS20 analytical column $(4 \times 250 \mathrm{~mm})$, and AG20 guard column $(4 \times 50 \mathrm{~mm})$. The $\mathrm{ClO}_{4}{ }^{-}$resin-water distribution coefficient $K_{\mathrm{d}}(\mathrm{mL} / \mathrm{g})$ was expressed as:

$$
K_{\mathrm{d}}=\frac{\left(C_{0}-C_{\mathrm{f}}\right) \times V / m}{C_{\mathrm{f}}}
$$

where $C_{0}$ and $C_{\mathrm{f}}$ are, respectively, the initial and final (equilibrium) concentrations of $\mathrm{ClO}_{4}^{-}(\mathrm{mg} / \mathrm{mL})$ in solution measured by IC, $V(\mathrm{~mL})$ is the volume of the sample solution and $m(\mathrm{~g})$ is the mass of resin.

Batch Equilibrium Desorption Studies. We carried out batch studies to investigate the desorption of $\mathrm{ClO}_{4}^{-}$from selected PEI and STY-DVB resins. For each resin, $0.1 \mathrm{~g}$ of dry media was first equilibrated overnight with a $50 \mathrm{~mL}$ solution of

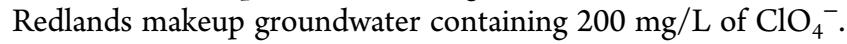
Following the determination of the amount of $\mathrm{ClO}_{4}{ }^{-}$sorbed by each resin using IC with EPA method $314.0^{3}$, the supernatant solutions were decanted. Each resin was subsequently washed twice with a $50 \mathrm{~mL}$ aliquot of deionized water to remove residual and unbound $\mathrm{ClO}_{4}^{-}$. Following this, each resin was equilibrated with an aqueous solution of $\mathrm{NaCl}$ (5.8 wt \%) to induce desorption through the exchange of $\mathrm{Cl}^{-}$ions with the sorbed $\mathrm{ClO}_{4}^{-}$ions. The percent of perchlorate desorbed $\left(F_{\text {desorbed }}\right)$ was expressed as follows:

$$
F_{\text {desorbed }}=100 \times\left[C_{\mathrm{f}} / C_{0}\right]
$$

where $C_{0}$ and $C_{f}$ are, respectively, the initial and final concentrations of $\mathrm{ClO}_{4}^{-}(\mathrm{mg} / \mathrm{L})$ in solution measured by IC.

Separation Factor Measurements. Batch studies were conducted to benchmark the selectivity of our most perchlorate-selective PEI resin against that of the A530-E STY-DVB resin. For this purpose, we used the binary separation factor as measure of selectivity. Following Clifford et al., ${ }^{23}$ the binary separation factor $\alpha_{i j}$ can be expressed as follows:

$$
\alpha_{\mathrm{i} / \mathrm{j}}=\frac{q_{\mathrm{i}} / C_{\mathrm{i}}}{q_{\mathrm{j}} / C_{\mathrm{j}}}
$$

where $q_{\mathrm{i}}(\mathrm{meq} / \mathrm{mL})$ and $\mathrm{q}_{\mathrm{j}}(\mathrm{meq} / \mathrm{mL})$ are, respectively, the concentrations of ions $i$ and $j$ in the resin phase and $C_{i}$ (meq/ $\mathrm{mL})$ and $C_{\mathrm{j}}(\mathrm{meq} / \mathrm{mL})$ are, respectively, the concentrations of ions $i$ and $j$ in the aqueous phase. Because chloride $\left(\mathrm{Cl}^{-}\right)$is the preferred exchange site for commercial perchlorate-selective resins, we measured three binary separation factors (SF): perchlorate-chloride SF $\left(\alpha_{\mathrm{ClO}_{4}^{-}} / \mathrm{Cl}^{-}\right)$, nitrate-chloride $\mathrm{SF}$ $\left(\alpha_{\mathrm{NO}_{3}^{-}} / \mathrm{Cl}^{-}\right)$and sulfate-chloride $\mathrm{SF}\left(\alpha_{\mathrm{SO}_{4}^{2-}} / \mathrm{Cl}^{-}\right)$. We used the procedure of Clifford et al. ${ }^{23}$ to measure the binary separation factors. For this purpose, $50 \mathrm{~mL}$ aliquots of binary mixtures of $\mathrm{ClO}_{4}{ }^{-} / \mathrm{Cl}^{-}, \mathrm{SO}_{4}{ }^{2-} / \mathrm{Cl}^{-}$, and $\mathrm{NO}_{3}{ }^{-} / \mathrm{Cl}^{-}$were, respectively, mixed and equilibrated for $24 \mathrm{~h}$ in a rotary shaker with 0.025 , $0.050,0.075,0.100$, and $0.150 \mathrm{~g}$ (dry weight equivalent) of resins in polypropylene vials to achieve target concentrations of (i) $2-20 \mathrm{ppb}$ for perchlorate and (ii) $10-50 \mathrm{ppm}$ for nitrate and sulfate. In all cases, the total ion concentration in each vial was equal to $\sim 5.0 \mathrm{meq} / \mathrm{L}^{23}$ Following equilibration, the concentrations of $\mathrm{ClO}_{4}{ }^{-}, \mathrm{NO}_{3}{ }^{-}, \mathrm{SO}_{4}{ }^{2-}$, and $\mathrm{Cl}^{-}$in the initial and supernatant solutions were measured by ion chromatography as previously described in the experimental section. The measured concentrations of $\mathrm{ClO}_{4}{ }^{-}, \mathrm{NO}_{3}{ }^{-}, \mathrm{SO}_{4}{ }^{2-}$, and $\mathrm{Cl}^{-}$were subsequently used to estimate the corresponding binary SF using eq 4. Each reported SF is the average of five measurements.

Column Studies. Column studies were conducted to benchmark the performance of our most perchlorate-selective PEI resin against that of the A-530E STY-DVB resin. To compare the operational capacity of these perchlorate-selective resins while reducing the length of the column experiments, we carried out accelerated breakthrough experiments using a Redlands makeup groundwater sample containing an initial $\mathrm{ClO}_{4}^{-}$concentration of $10 \mathrm{mg} / \mathrm{L}$. Following Tripp and Clifford, ${ }^{7}$ the ion exchange mini-column consisted of $3 \mathrm{~mL}$ of resins $\left(\mathrm{Cl}^{-}\right.$form $)$that were packed in glass columns $(0.7 \mathrm{~cm}$ ID) with a bed depth of $8 \mathrm{~cm}$. Test solutions were pumped through the mini-columns with a flow rate of $3.0 \mathrm{~mL} / \mathrm{min}$ using a peristaltic pump (model EP-1 Econo Pump from Bio-Rad Laboratories). The system had an empty bed contact time of 1 $\mathrm{min}$ and a superficial linear velocity of $8 \mathrm{~cm} / \mathrm{min}(1.0 \mathrm{BV} / \mathrm{min})$. The concentrations of $\mathrm{ClO}_{4}^{-}$in the column effluents were analyzed by IC using EPA method 314.0. ${ }^{3}$ The volume of water treated $\left(\mathrm{m}^{3}\right)$ per volume of media $\left(\mathrm{m}^{3}\right)$ at $50 \%$ breakthrough of perchlorate (i.e., $C / C_{0}=0.5$ ) was used as measure of resin operational capacity (OC). In all cases, the OC was determined by linear interpolation using the two closest measured throughput values.

\section{RESULTS AND DISCUSSION}

Synthesis of Base PEI Beads by Suspension Polymerization. Perchlorate-selective resins (PSRs) such as the commercial A-530 resin are prepared by functionalization of cross-linked STY-DVB beads using a two-step process. ${ }^{9-11}$ In the first step, chloromethyl groups are attached to the STYDVB beads via a Friedel-Crafts reaction involving the aromatic rings of the resin and an alkyl halide such as chloromethoxymethane in the presence of a Lewis acid catalyst. In the second step, the chloromethyl groups are reacted with a trihexyl amine followed by reaction with a triethyl amine to produce a bifunctional resin with trihexyl/triethyl ammonium chloride $\left(\mathrm{Cl}^{-}\right)$exchange sites. While the amination of chloromethylated STY-DVB beads is a facile reaction, which takes place in high yield, several side-reactions including the secondary crosslinking of the bead aromatic rings via "methylene bridging" occur during chlomethylation. This reduces the number of functional sites available for amination. ${ }^{9-11}$ and as a result of this, the maximum reported $\mathrm{SBEC}_{\mathrm{v}}$ for anion-exchange STY-DVB resins with methyl ammonium chloride $\left(\mathrm{Cl}^{-}\right)$exchange sites is 1.4 
eq/L. ${ }^{10,23}$ For perchlorate-selective STY-DVB resins, reported $\mathrm{SBEC}_{\mathrm{v}}$ values range from 0.5 to $0.8 \mathrm{eq} / \mathrm{L}^{12,23} \mathrm{In}$ our efforts to develop PSRs with higher exchang capacity than those of commercial STY-DVB resins, we selected branched polyethyleneimine (PEI) as precursor both for its high content of reactive primary/secondary amine groups and availability from commercial sources. ${ }^{24,25}$ Due to the solubility of PEI macromolecules in water, we employed a surfactant-stabilized inverse suspension of water-in-toluene ${ }^{20}$ to prepare the base PEI beads possessing high density of amine groups as described in Section 1 of the SI. Note that the size of commercial STYDVB resin beads range from 300 to $1200 \mu \mathrm{m}$ with a mean diameter of $700 \mu \mathrm{m} .{ }^{10}$ Consequently, we first optimized the reaction conditions to prepare PEI beads with an average diameter comparable to those of commercial STY-DVB resins. During suspension polymerization, the size of the droplets in the dispersed phase controls the size of the polymeric beads. ${ }^{26}$ In the case of water-in-oil suspensions, the size of water droplets depends on several variables including stirring speed, surfactant concentration, and the viscosities of the oil and water phases. ${ }^{26}$ Figure 1 illustrates the effects of suspension stirring
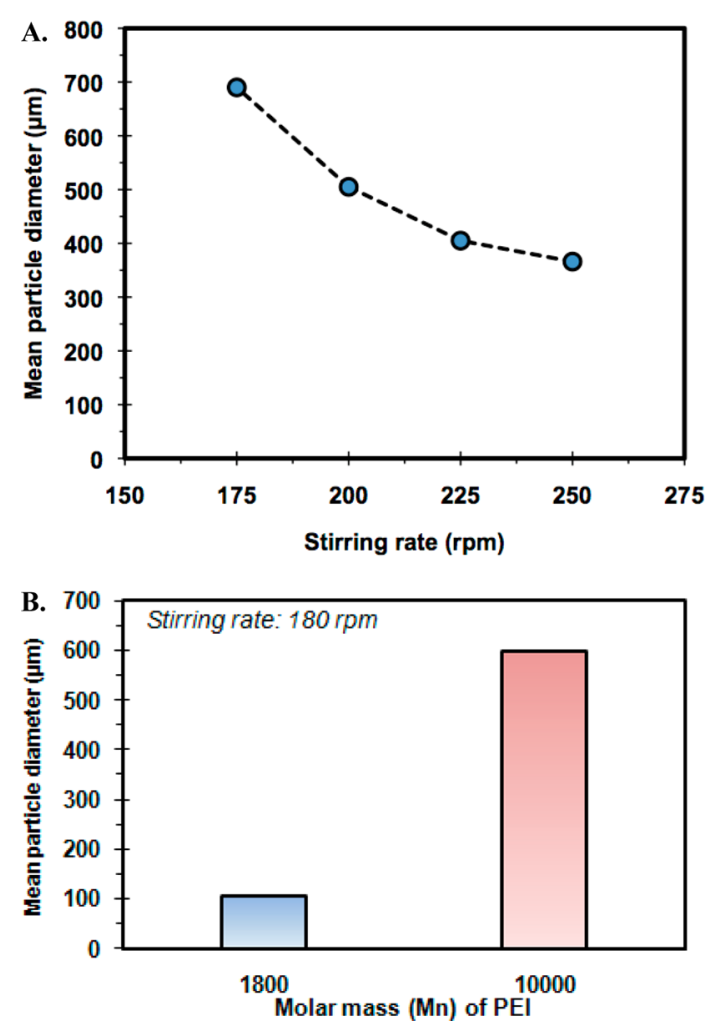

Figure 1. Synthesis of PEI beads with cross-linked epichlorohydrin $(\mathrm{ECH})$ matrices: Effects of suspension stirring rate $(\mathrm{A})$ and PEI molecular weight (B) on particle size. In these experiments, the NCR was kept constant and equal to 33 wt $\%$.

rate and PEI molar mass on the size of beads prepared by crosslinking hyperbranched PEI with epichlorohydrin (ECH) in suspensions of water-in-toluene as described in reaction Scheme $1 S$ of the SI. In these experiments, we kept the nominal cross-linking ratio (NCR) constant and equal to $33 \mathrm{wt}$ $\%$. For convenience, the NCR was used as a surrogate for the actual degree of cross-linking. Following Sherrington, ${ }^{11}$ the NCR was taken as the wt\% of cross-linker (ECH) used to prepare the base PEI resin beads. Figure 1 shows that we were able to prepare base PEI beads with average diameter of 694 $\mu \mathrm{m}$ by optimizing the stirring rate and using a precursor PEI macromolecule of molar mass $M_{n}$ equal to $10000 \mathrm{Da}$.

Synthesis of Perchlorate-Selective Resins by Functionalization of Base PEI Beads. The synthesis of our new PSRs was carried out by alkylation of base PEI beads to afford quaternized PEI beads with ammonium chloride $\left(\mathrm{Cl}^{-}\right)$ exchange sites. It is well-known that the affinity of STY-DVB resins for monovalent anions increase with anion size and hydrophobicity. ${ }^{6,7}$ Table $1 \mathrm{~S}$ of the SI shows that $\mathrm{ClO}_{4}{ }^{-}$has a larger ionic radius and hydration free energy, which is much less favorable than those of anions such $\mathrm{Cl}^{-}, \mathrm{NO}_{3}{ }^{-}, \mathrm{HCO}_{3}{ }^{-}$, and $\mathrm{SO}_{4}{ }^{2-}$. This suggests that anion-exchange STY-DVB resins tend to exhibit a higher affinity for large and poorly hydrated anions such as $\mathrm{ClO}_{4}^{-}$. However, the performance of perchlorateselective STY-DVB is strongly affected by anions such as sulfate $\left(\mathrm{SO}_{4}{ }^{2-}\right)$ and nitrate $\left(\mathrm{NO}_{3}{ }^{-}\right)$as their concentrations in most contaminated groundwater are 1-3 orders of magnitude greater than that of $\mathrm{ClO}_{4}{ }^{-}$. Both $\mathrm{SO}_{4}{ }^{2-}$ and $\mathrm{NO}_{3}{ }^{-}$compete for the exchange sites $\left(\mathrm{Cl}^{-}\right)$of perchlorate-selective STY-DVB resins. ${ }^{6,7}$ Based on our earlier studies of $\mathrm{ClO}_{4}{ }^{-}$binding to a fifth generation $\left(\mathrm{G} 5-\mathrm{NH}_{2}\right)$ poly(propyleneimine) [PPI] dendrimer and a fourth generation $\mathrm{G} 4-\mathrm{NH}_{2}$ poly(amidoamine) [PAMAM] dendrimer, ${ }^{27}$ we expected that branched PEI resins with hydrophobic cavities containing quaternary amine chloride groups would exhibit higher affinity for $\mathrm{ClO}_{4}{ }^{-}$over competing anions in aqueous solutions. Previous studies from Oak Ridge National Laboratory have also shown that a bifunctional STYDVB resin with trihexyl and triethyl ammonium chloride groups can selectively remove trace amounts of large and poorly hydrated anions such as $\mathrm{ClO}_{4}{ }^{-}$and $\mathrm{TcO}_{4}{ }^{-}$(Table $1 \mathrm{~S}$ of the SI) in contaminated groundwater in the presence of competing anions. ${ }^{6,22}$ Therefore, we employed a multipronged approach to synthesize new PSRs with high exchange capacity. First, we evaluated the effects of resin degree of cross-linking and water content on $\mathrm{ClO}_{4}^{-}$binding affinity to PEI resins with hexyl ammonium chloride groups. For this purpose, we prepared a series of ECH-cross-linked PEI beads (Table $2 S$ of the SI) with varying NCR. These resins were subsequently reacted with bromohexane to afford PEI resins with hexyl ammonium chloride $\left(\mathrm{Cl}^{-}\right)$exchange sites as described in reaction Scheme $5 S$ of the SI. Figure 2 illustrates the effect of cross-linking on resin water content and perchlorate resinwater distribution coefficient. Following Gu and Brown, ${ }^{6}$ we utilized the perchlorate resin-water $K_{\mathrm{d}}$ as a measure of a resin "efficiency for sorbing $\mathrm{ClO}_{4}^{-}$from the solution phase". Figure 2 illustrates the effect of the NCR on both the water contents and $K_{\mathrm{d}}$ of ECH-cross-linked PEI beads with hexyl ammonium chloride $\left(\mathrm{Cl}^{-}\right)$exchange sites. The $K_{\mathrm{d}}$ values were taken as the slopes of the linear sorption isotherms given in Figure $4 \mathrm{~S}$ of the SI. Note that as the NCR of the PEI resins increases, their water contents decrease and then level off followed by a slight increase. In contrast, their $K_{\mathrm{d}}$ values increase to a maximum followed by a decrease and a slight increase as the NCR increases. A maximum $K_{d}$ value $(13922 \mathrm{~mL} / \mathrm{g})$ is reached when the NCR and water contents of the ECH-cross-linked PEI beads with hexyl ammonium chloride groups are, respectively, equal to $33 \mathrm{wt} \%$ and $58 \mathrm{wt} \%$. At the present time, we have no definitive explanation for this behavior. We speculate that the $\mathrm{K}_{\mathrm{d}}$ trend shown in Figure 2 could be attributed to a decrease in resin moisture content and accessibility due to both matrix cross-linking and functionalization. 

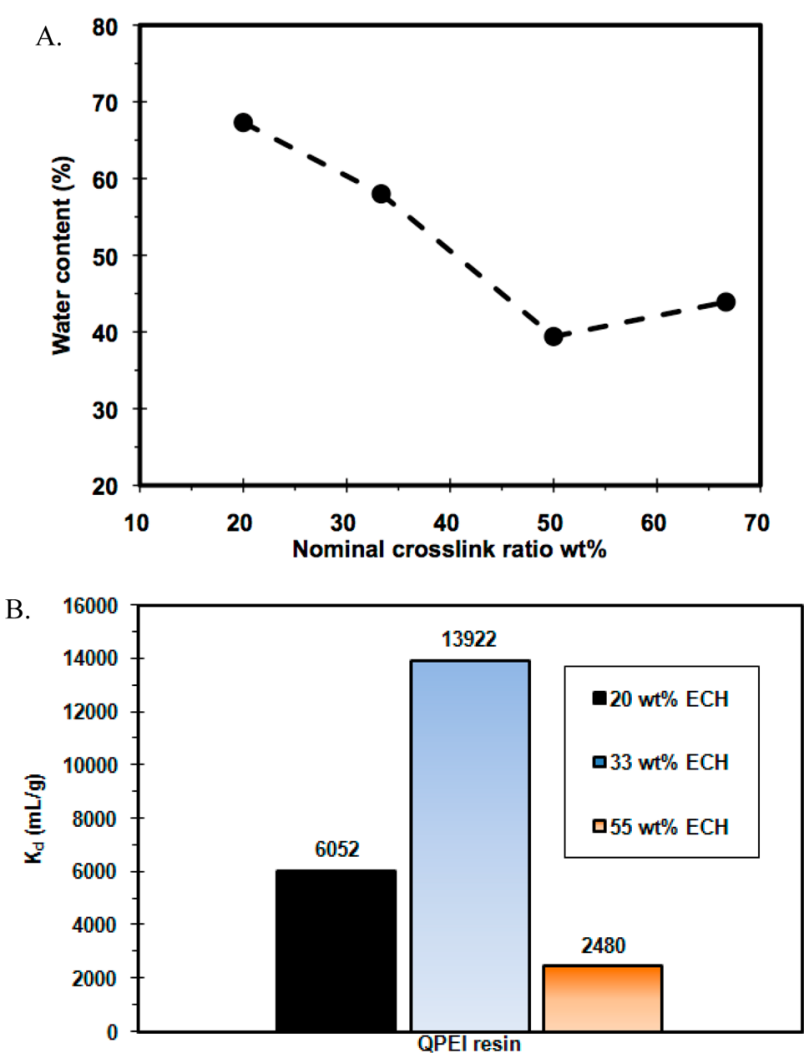

Figure 2. Synthesis of PEI resins with cross-linked epichlorohydrin $(\mathrm{ECH})$ matrices and hexyl quaternary ammonium chloride $\left(\mathrm{Cl}^{-}\right)$ exchange groups: Effect of cross-linking degree on resin water content (A) and $\mathrm{ClO}_{4}^{-}$distribution coefficients $\left(K_{\mathrm{d}}\right)$ in redlands makeup groundwater (B). The nominal cross-link ratio (NCR) was used a surrogate for the resin degree of cross-linking. The $K_{d}$ values were derived from batch equilibrium sorption studies (Figure $4 S$ of the SI). In these experiments, $0.025,0.050$, and $0.10 \mathrm{~g}$ of media (dry-weight) were contacted with $625 \mathrm{ppb} \mathrm{ClO}_{4}{ }^{-}$in Redlands makeup water for 24 h.

We also evaluated the effects of cross-linker chemistry on perchlorate binding. For this purpose, we first prepared a base PEI bead using a mixture ECH and 1-bromo-3-chloropropane (BCP) to cross-link a precursor PEI with molar mass $M_{\mathrm{n}}=$ $10000 \mathrm{Da}$ as described in reaction Scheme $2 \mathrm{~S}$ of the SI. This ECH/BCP cross-linked PEI resin has an nominal cross-link ratio of 41 wt $\%$ with a BCP:ECH molar ratio of $\sim 1.3: 1$. We subsequently reacted this base PEI resin with bromohexane (Scheme 5S of the SI) to afford a quaternized PEI resin with a cross-linked ECH/BCP matrix and hexyl ammonium chloride exchange sites. Not surprisingly, Figure 3 shows that the ECH/ BCP cross-linked PEI resin with hexyl ammonium chloride groups has a $\mathrm{ClO}_{4}^{-}$resin-water distribution coefficient $\left(K_{\mathrm{d}}=\right.$ $29768 \mathrm{~mL} / \mathrm{g}$ ) that is larger than that of the corresponding ECH-cross-linked resin $\left(K_{d}=13922 \mathrm{~mL} / \mathrm{g}\right)$. We attribute the higher $K_{\mathrm{d}}$ value of the PEI resin with ECH/BCP cross-linkers to a more hydrophobic matrix with a lower water content (35 wt \%) as shown in Table 3S of the SI.

Batch Sorption and Desorption Studies. Building upon the results of the previous investigations, we prepared a series of quaternized PEI resins with ammonium chloride exchange sites (Table 2) containing alkyl groups of varying chain lengths including methyl (QPEI-1), butyl (QPEI-2), hexyl (QPEI-3), hexyl/ethyl (QPEI-4), and isobutyl/propyl (QPEI-5). All these resins were synthesized by alkylation of a base PEI bead (PEI-

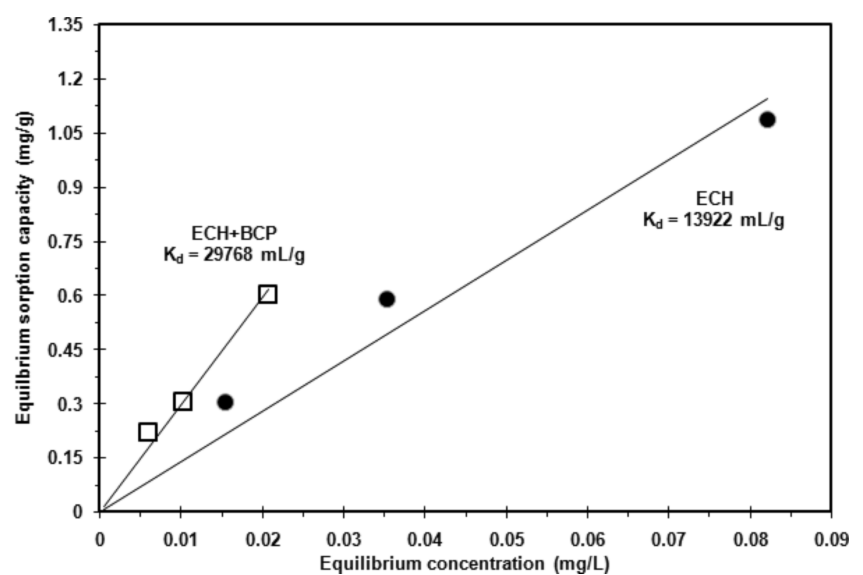

Figure 3. Synthesis of PEI Resins with Hexyl Quaternary Ammonium Chloride $\left(\mathrm{Cl}^{-}\right)$Exchange Groups: Effect of Cross-linker Chemistry on $\mathrm{ClO}_{4}^{-}$Distribution Coefficients $\left(K_{\mathrm{d}}\right)$ in Redlands Makeup Groundwater. For the $\mathrm{ECH}$ cross-linker, the nominal cross-link ratio (NCR) was $33 \mathrm{wt} \%$. For the mixture of ECH/BCP cross-linkers, the total $\mathrm{NCR}$ was equal to $41 \mathrm{wt} \%$ with a BCP:ECH molar ratio of $\sim 1.3: 1$. The $K_{\mathrm{d}}$ values were derived from batch equilibrium sorption studies (Figure $4 \mathrm{~S}$ of the SI). In these experiments, 0.025, 0.050, and $0.10 \mathrm{~g}$ of media (dry-weight) were contacted with $625{\mathrm{ppb} \mathrm{ClO}_{4}}^{-}$in Redlands makeup groundwater (Table 1) for $24 \mathrm{~h}$.

6) with mixed $\mathrm{ECH} / \mathrm{BCP}$ cross-linker, nominal cross-link ratio of 51 wt \% and water content of 58.6 wt \% (Table $2 S$ of the SI). The SI provides a detailed description of the reaction schemes (Schemes 4S-8S) and synthetic procedures used to prepare the quaternized PEI (QPEI) resins listed in Table 2. Batch sorption studies were carried out to screen the performance of the QPEI resins listed in Table 2 against representative STY-DVB resins in a Redlands makeup groundwater solution (Table 1). Table 2

Table 1. Concentration of Competing Anions in the Redlands Makeup Ground Water ${ }^{a}$

$\begin{array}{lcc}\text { anion } & \text { concentration } & \text { unit } \\ \mathrm{Cl}^{-} & 106 & \mathrm{mg} / \mathrm{L} \\ \mathrm{NO}_{3}{ }^{-} & 31 & \mathrm{mg} / \mathrm{L} \\ \mathrm{HCO}_{3}{ }^{-} & 183 & \mathrm{mg} / \mathrm{L} \\ \mathrm{SO}_{4}{ }^{2-} & 49 & \mathrm{mg} / \mathrm{L}\end{array}$

${ }^{a_{T}}$ The test solution was a simulation of a typical contaminated groundwater found in Redlands (CA, USA). It was utilized in a previous study of perchlorate-selective resins conducted by Oak Ridge National Laboratory as described in the report by Gu et al. (See ref 22). The makeup Redlands groundwater was prepared by dissolving 3 $\mathrm{mM}$ of $\mathrm{NaHCO}_{3}, 3 \mathrm{mM}$ of $\mathrm{NaCl}, 0.5 \mathrm{mM}$ of $\mathrm{Na}_{2} \mathrm{SO}_{4}$, and $0.5 \mathrm{mM}$ of $\mathrm{NaNO}_{3}$ in deionized water.

lists the estimated $K_{d}$ values for the QPEI resins and STY-DVB resins. Each reported $K_{d}$ value is the average of three replicate measurements (with a standard deviation of $5 \%$ ) after $24 \mathrm{~h}$ of equilibration time. The magnitudes of the $K_{\mathrm{d}}$ values for the QPEI 1-3 resins clearly indicate that their affinity for $\mathrm{ClO}_{4}{ }^{-}$ increase with resin hydrophobicity (Table 2). This trend is consistent with the results of our previous studies showing that a $\mathrm{G} 5-\mathrm{NH}_{2}$ PPI dendrimer provides a more favorable environment for the partitioning of $\mathrm{ClO}_{4}{ }^{-}$anions than the more hydrophilic G4- $\mathrm{NH}_{2}$ PAMAM dendrimer in aqueous solutions and model electrolyte solutions. ${ }^{27}$ This observation is also consistent with the higher affinity of $\mathrm{ClO}_{4}{ }^{-}$for the DOWEX-1 STY-DVB resin $\left(K_{\mathrm{d}}=97398 \mathrm{~mL} / \mathrm{g}\right)$ when compared to the 
Table 2. Perchlorate Resin-Water Distribution Coefficients $\left(K_{d}\right)$ for Selected Commercial and QPEI Resins in a Redlands Makeup Groundwater Solution ${ }^{a}$

\begin{tabular}{|c|c|c|c|c|c|}
\hline resin & $f_{\mathrm{SBEC}_{\mathrm{v}}}(\mathrm{eq} / \mathrm{L})$ & water content (\%) & $g_{K_{\mathrm{d}}}(\mathrm{mL} / \mathrm{g})$ & matrix & ammonium chloride group \\
\hline${ }^{b} \mathrm{~A}-850 \mathrm{E}$ & 1.25 & 48 & 3617 & ACR-DVB & trimethyl \\
\hline${ }^{c}$ DOWEX-1 & 1.40 & 45 & 97398 & STY-DVB & trimethyl \\
\hline${ }^{d} \mathrm{~A}-530 \mathrm{E}$ & 0.60 & 53 & 195422 & STY-DVB & trihexyl and triethyl \\
\hline${ }^{e} \mathrm{QPEI}-1$ & 2.70 & 42 & 7359 & PEI & methyl \\
\hline${ }^{e} \mathrm{QPEI}-2$ & 1.80 & 44 & 48906 & PEI & butyl \\
\hline${ }^{e} \mathrm{QPEI}-3$ & 0.70 & 24 & 233318 & PEI & hexyl \\
\hline${ }^{e} \mathrm{QPEI}-5$ & 1.23 & 38 & 123098 & PEI & isobutyl + propyl \\
\hline
\end{tabular}

${ }^{a}$ During these experiments, perchlorate sorption onto the resins was measured by mixing $50 \mathrm{mg}$ (dry weight equivalent) of media with $50 \mathrm{~mL}$ of a test solution containing $625 \mathrm{ppb}$ of $\mathrm{ClO}_{4}{ }^{-}{ }^{b}$ Purolite A-850E: Acrylic-divinylbenzene (ACR-DVB) resin (Gel). ${ }^{c}$ DOWEX-1: Styrene-divinylbenzene (STY-DVB) resin (Gel). ${ }^{d}$ Purolite A-530E: Bifunctional perchlorate-selective STY-DVB resin (Macroporous). ${ }^{e}$ QPEI: Quaternized polyethyleneimine (PEI) resins. These resins were synthesized using the procedures described in the SI. ${ }^{f}{ }_{S B E C}$ : Strong-base exchange capacity. The $\mathrm{SBEC}_{\mathrm{v}}$ of each resin was measured by Mohr titration using the procedures described in the section "Experimental Methods and Procedures". ${ }^{g} K_{\mathrm{d}}$ : Perchlorate resin-water distribution coefficient. Each $K_{\mathrm{d}}$ value reported in Table 2 is the average of three replicate measurements (with a standard deviation of 5\%) after $24 \mathrm{~h}$ of equilibration time.

more hydrophilic acrylic-DVB resin Purolite A-850E $\left(K_{\mathrm{d}}=\right.$ $3617 \mathrm{~mL} / \mathrm{g}$ ) (See Table 2).

Table 2 also shows that the QPEI-3 resin with hexyl quaternary ammonium groups has a $K_{\mathrm{d}}$ value that is larger than that of the A-530E resin with trihexyl and triethyl quaternary ammonium groups. We were able to increase the $\mathrm{SBEC}_{\mathrm{v}}$ of the QPEI-3 resin to $1.4 \mathrm{eq} / \mathrm{L}$ while maintaining its high affinity for $\mathrm{ClO}_{4}^{-}\left(K_{\mathrm{d}}=295490 \mathrm{~mL} / \mathrm{g}\right)$ via a secondary alkylation with bromoethane (QPEI-4) as described in reaction Scheme 7S of the SI. Note that a key limitation of $K_{\mathrm{d}}$ as a measure of sorption affinity is its dependence on several factors including the initial concentration of the target anions and the resin exchange capacity. ${ }^{6}$ Consequently, we also measured $\mathrm{ClO}_{4}{ }^{-}$sorption onto the QPEI-4 and A-530 E resins as a function of concentration. Figure 4 shows that the sorption isotherms of the QPEI-3 and A-530 E resins are linear when the initial $\mathrm{ClO}_{4}{ }^{-}$concentration ranges from $0.5 \mathrm{mg} / \mathrm{L}$ to $10 \mathrm{mg} / \mathrm{L}$. In this case, the $\mathrm{ClO}_{4}^{-}$resin-water partition coefficients $\left(K_{\mathrm{d}}\right)$ are equal to the slopes of the linear sorption isotherms of the resins. Table 2 and Figure 4 show that the single point $K_{d}$ value

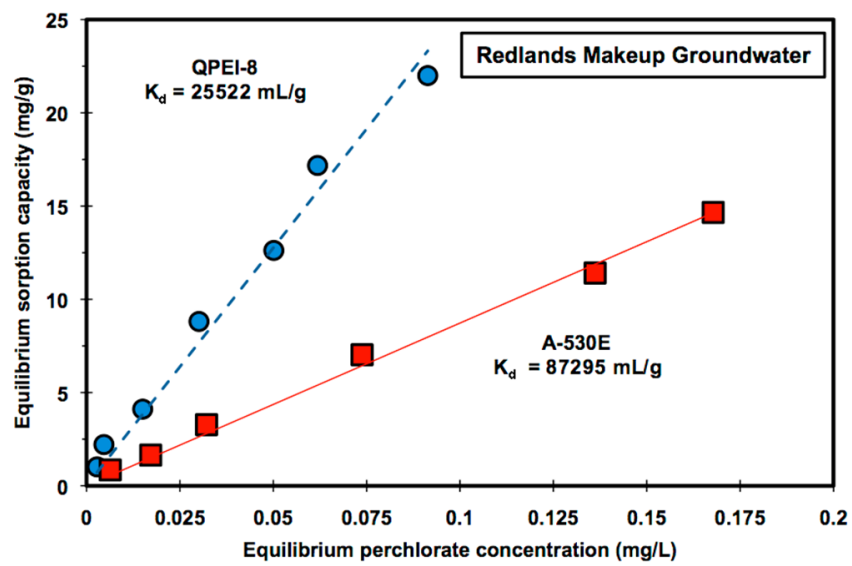

Figure 4. Perchlorate resin-water distribution coefficients $\left(K_{d}\right)$ for the QPEI-4 and A-530E resins in redlands makeup groundwater. The $K_{d}$ values were derived from batch equilibrium sorption studies. In these experiments, perchlorate sorption onto the resins $(24 \mathrm{~h})$ was measured by mixing $50 \mathrm{mg}$ (dry weight equivalent) of media (for $24 \mathrm{~h}$ ) with 50 $\mathrm{mL}$ of Redlands makeup groundwater with $\mathrm{ClO}_{4}^{-}$concentration ranging from 0.5 to $10 \mathrm{mg} / \mathrm{L}$. of the A-530E resin $(195422 \mathrm{~mL} / \mathrm{g}$ ) (Table 2) is 2.66 times larger than its $K_{d}$ value $(73247 \mathrm{~mL} / \mathrm{g})$ from the linear sorption isotherms (Figure 4). In contrast, the $K_{d}$ value of the QPEI-4 resin $(254890 \mathrm{~mL} / \mathrm{g})$ in the linear sorption range is comparable (Figure 4) to its single point $\mathrm{K}_{\mathrm{d}}$ value $(295490 \mathrm{~mL} / \mathrm{g})$ reported in Table 2. We primarily attribute this difference between the two resins to the higher strong-base exchange capacity of the QPEI-4 resin (Table 2).

Although the resin-water distribution coefficient $\left(K_{d}\right)$ can provide valuable insight into the affinity of a sorbent for a given ion, the regeneration efficiency of a resin is a critical measure of its selectivity. ${ }^{28}$ A low regeneration efficiency of resin can be ascribed to strong interactions between counterions (e.g., $\mathrm{ClO}_{4}^{-}$) and resin exchange sites (e.g., hexyl quaternary ammonium chloride groups). ${ }^{28} \mathrm{We}$ carried out batch studies to measure the desorption of $\mathrm{ClO}_{4}^{-}$from selected QPEI and commercial resins in $1.0 \mathrm{M} \mathrm{NaCl}$ (5.8 wt \%) solution as a function of equilibration time. Figure 5 shows that the resins

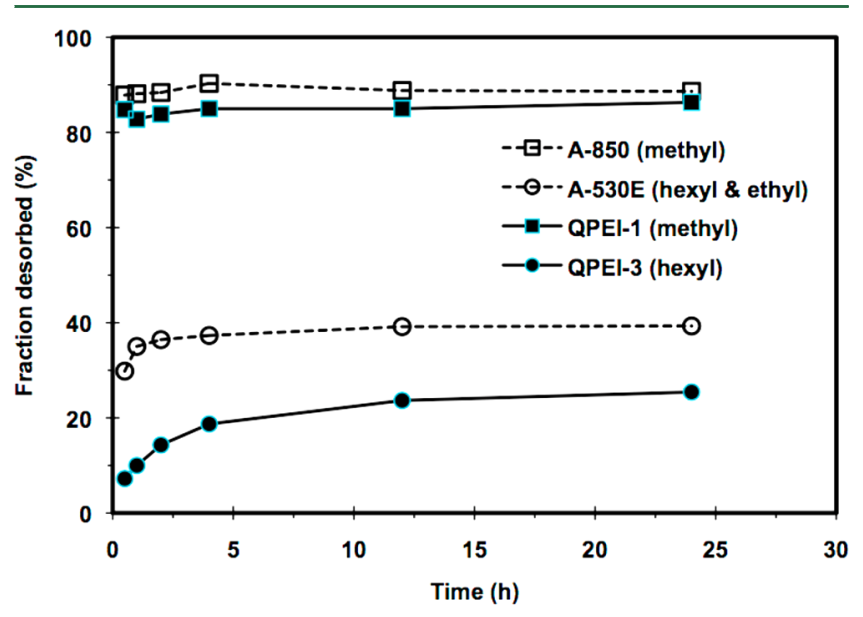

Figure 5. Perchlorate desorption from selected PEI and STY-DVB resins in $1.0 \mathrm{M}$ sodium chloride $(\mathrm{NaCl})$ solution (5.8 wt \%). For the desorption experiments, $0.1 \mathrm{~g}$ of dry media was first equilibrated overnight with a $50 \mathrm{~mL}$ solution of Redlands makeup groundwater containing $200 \mathrm{mg} / \mathrm{L}$ of $\mathrm{ClO}_{4}^{-}$. Following this, each resin was equilibrated with an aqueous solution of $\mathrm{NaCl}(5.8 \mathrm{wt} \%)$ to induce desorption through the exchange of $\mathrm{Cl}^{-}$ions with the sorbed $\mathrm{ClO}_{4}^{-}$ ions. 
with the lowest $K_{d}$ values (A-850 and QPEI-1) have the largest extent of $\mathrm{ClO}_{4}^{-}$desorption, that is, greater than $80 \%$ in all cases. In contrast, the resin with the largest (QPEI-4) value exhibits the lowest extent of $\mathrm{ClO}_{4}{ }^{-}$desorption, that is, less than $25 \%$ in all cases. A deeper insight into the selectivity of a resin for specific ions can also be gleaned by comparing their relative separation factors. Table 3 indicates that the perchlorate-

Table 3. Relative Separation Factors for QPEI-4 and A-530E Resins $^{a}$

$\begin{array}{cccc}\text { resin } & { }^{a} \alpha_{\mathrm{ClO}_{4}^{-}} / \mathrm{Cl}^{-} & { }^{b} \alpha_{\mathrm{SO}_{4}^{2-} / \mathrm{Cl}^{-}} & { }^{c} \alpha_{\mathrm{NO}_{3}^{-}} / \mathrm{Cl}^{-} \\ { }^{d} \mathrm{QPEI}-4 & 523 \pm 29.5 & 28.6 \pm 0.04 & 4.79 \pm 0.07 \\ { }^{e} \mathrm{~A}-530 \mathrm{E} & 597 \pm 2.16 & 14.7 \pm 0.40 & 4.66 \pm 0.01\end{array}$

${ }^{a}$ These experiments were carried using the procedures developed by Clifford et al. ${ }^{23}$. ${ }^{a} \alpha_{\mathrm{ClO}_{4}^{-}} / \mathrm{Cl}^{-}$: Perchlorate-chloride separation factor ${ }^{b} \alpha_{\mathrm{SO}_{4}^{2-} / \mathrm{Cl}^{-}}$: Sulfate-chloride separation factor ${ }^{c} \alpha_{\mathrm{NO}_{3}^{-} / \mathrm{Cl}^{-}}$: Sulfatechloride separation factor ${ }^{d}$ QPEI-4: Perchlorate-selective PEI resin (Table 2). ${ }^{e}$ A-530E: Perchlorate-selective STY-DVB resin (Table 2).

chloride separation factor (SF) of the QPEI-4 resin (523 \pm $29.5)$ is comparable to that of the A-530E resin $(597 \pm 2.16)$. Similarly, the nitrate-chloride SF of the QPEI-4 resin (4.79 \pm $0.07)$ is equal to that of the A-530E resin $(4.66 \pm 0.01)$. These results suggest that the QPEI-4 and A-530E resins have comparable selectivity for perchlorate and nitrate. Not surprisingly, the QPEI-4 resin exhibits a higher affinity for sulfate. Table 4 shows that the sulfate-chloride SF of the QPEI-

Table 4. Estimated $\mathrm{ClO}_{4}{ }^{-}$Operational Capacities for QPEI-4 and A-530E Resins in Redland Makeup Groundwater ${ }^{a}$

$\begin{array}{ccccccc}\text { resin } & \begin{array}{c}{ }^{b} \mathrm{SBEC}_{\mathrm{v}} \\ (\mathrm{eq} / \mathrm{L})\end{array} & \begin{array}{c}\text { water } \\ \text { content } \\ (\%)\end{array} & \begin{array}{c}{ }^{c} \text { particle } \\ \text { size }(\mu \mathrm{m})\end{array} & \begin{array}{c}{ }^{d} \mathrm{OC} \\ (\mathrm{BV})\end{array} & \begin{array}{c}{ }^{e} \mathrm{OC} \\ \text { ratio }\end{array} & \begin{array}{c}f_{\mathrm{SBEC}_{\mathrm{v}}} \\ \text { ratio }\end{array} \\ { }^{g} \mathrm{QPEI}-4 & 1.4 & 25 & 694 & 7558 & 2.36 & 2.33 \\ { }^{h} \mathrm{~A}-530 \mathrm{E} & 0.6 & 53 & 634 & 3200 & 1.0 & 1.0\end{array}$

${ }^{a}$ We used a Redlands makeup groundwater solution (Table 1) containing an initial $\mathrm{ClO}_{4}{ }^{-}$concentration of $10 \mathrm{mg} / \mathrm{L}$ to reduce the duration of the experiments by accelerating the breakthrough of $\mathrm{ClO}_{4}{ }^{-}$ through the columns (Figure 6). ${ }^{b} \mathrm{SBEC}_{\mathrm{v}}$ : Strong-base exchange capacity. ${ }^{c}$ Particle Size: Median particle diameter $\left(D_{50}\right)$ determined by particle size analysis using a Malvern Mastersizer (Figure $3 \mathrm{~S}$ of the SI). ${ }^{d}$ OC: Operational capacity. Taken as the volume of water of effluent water (BV) at $50 \%$ breakthrough (Figure 6). ${ }^{e} \mathrm{OC}$ Ratio: Ratio of the operational capacity of the QPEI-4 resin to that of the A-530E resin.

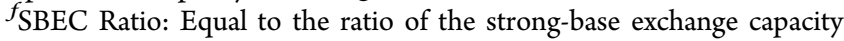
of a PEI resin to that of the Purolite A-530E resin. ${ }^{g} \mathrm{QPEI}-4$ : Perchlorate-selective PEI resin (Table 2). ${ }^{h}$ A-530E: Perchlorateselective STY-DVB resin (Table 2).

4 resin $(28.6 \pm 0.04)$ is approximately twice that of the A-530E resin $(14.7 \pm 0.40)$. These results are consistent with those reported by Weber and Clifford. ${ }^{29}$ During their investigations of the binding of monovalent and divalent ions to anionexchange resins with quaternary ammonium chloride $\left(\mathrm{Cl}^{-}\right)$ exchange sites, they found that resins with "closely-spaced $\mathrm{N}$ containing (amine) functional groups" are more selective for divalent anions (e.g., $\mathrm{SO}_{4}{ }^{2-}$ ). ${ }^{29}$ Because the QPEI-4 resin contains more "closely-spaced" amine groups than the STYDVB A-530E, it is not surprising that it also exhibits a higher sulfate-chloride SF. Given that QPEI-4 resin has a higher perchlorate $K_{d}$ value than the A-530E resin with comparable perchlorate-chloride and nitrate-cloride separation factors, the performance advantage of the QPEI-4 resin can be attributed for the most part to its higher exchange capacity (Table 2).

Column Studies. The overall results of the characterization studies showed that the QPEI-4 resin [with mixed ECH/BCH cross-linker and hexyl/ethyl ammonium chloride exchange sites] has a strong-base exchange capacity $\left(\mathrm{SBEC}_{\mathrm{v}}\right)$ of $1.4 \mathrm{eq} / \mathrm{L}$ (Table 2), which is 2.33 times larger than of the A-530E resin. In addition, both the A530-E and QPEI-4 resins have comparable perchlorate selectivity and particle size distribution with mean particle diameters that are, respectively, equal to 635 and $694 \mu \mathrm{m}$ (Figure $2 \mathrm{~S}$ of SI). The sorption and desorption studies (Figures 4 and 5) also suggest that the $\mathrm{ClO}_{4}{ }^{-}$affinity of the QPEI-4 resin (i.e., $K_{d}$ value) is larger than of the A-530E resin in the Redlands makeup groundwater with initial perchlorate concentrations of $0.5-10 \mathrm{mg} / \mathrm{L}$ (Figure 4). To further benchmark the performance of the QPEI-4 resin against that of the A-530E STY-DVB resin, we carried out column studies of $\mathrm{ClO}_{4}^{-}$extraction from a Redlands makeup groundwater sample (Table 1). We utilized a Redlands makeup groundwater solution containing an initial $\mathrm{ClO}_{4}{ }^{-}$concentration of $10 \mathrm{mg} / \mathrm{L}$ to reduce the duration of the experiments by accelerating the breakthrough of perchlorate through the columns. Figure 6 shows the $\mathrm{ClO}_{4}{ }^{-}$breakthrough curves of

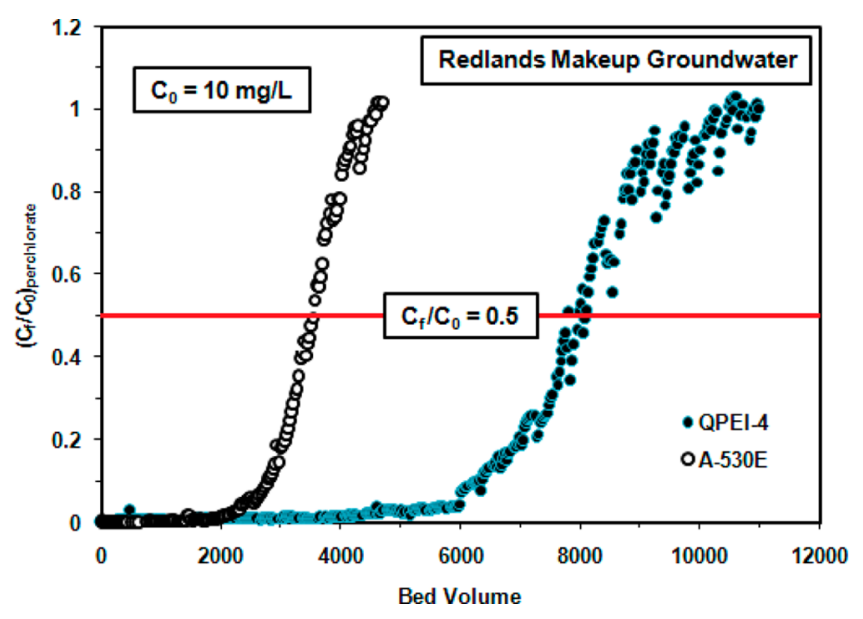

Figure 6. Perchlorate breakthrough curves for QPEI-4 and A-530E resins in redlands makeup groundwater. We utilized a Redlands makeup groundwater solution (Table 1) containing an initial $\mathrm{ClO}_{4}{ }^{-}$ concentration of $10 \mathrm{mg} / \mathrm{L}$ to reduce the duration of the experiments by accelerating the breakthrough of perchlorate through the columns. The volume of effluent water $(\mathrm{BV})$ at $50 \%$ breakthrough (i.e., $\left(C_{\mathrm{f}} / C_{\mathrm{o}}\right.$ $=0.5$ ) was employed as a measure of the operational capacity (OC) for perchlorate extraction from Redlands makeup groundwater.

the QPEI-4 and A-530E resins. Table 4 lists the operational capacity of the two resins in the Redlands makeup groundwater. Figure 6 and Table 4 shows that the QPEI-4 outperforms the commercial A-530E resin by a factor of 2.33 in OC for perchlorate extraction from Redlands makeup groundwater containing an effluent $\mathrm{ClO}_{4}{ }^{-}$concentration of $10 \mathrm{mg} / \mathrm{L}$. Not surprisingly, the OC advantage of the QPEI-4 resin (OC ratio = 2.36) over the A-530E resin matches the corresponding exchange capacity advantage $\left(\mathrm{SBEC}_{\mathrm{v}}\right.$ ratio $\left.=2.33\right)$ listed in Table 4.

Environmental Implications. As stated in the Introduction, IX with selective and disposable resins is the most widely used process for treating drinking groundwater sources with influent $\mathrm{ClO}_{4}{ }^{-}$concentration $<100 \mathrm{ppb}$. Gu et al. ${ }^{30}$ showed that 
selective media such as the A-530E STY-DVB resin was able to treat more than 100000 bed volumes (BV) of contaminated groundwater with an influent $\mathrm{ClO}_{4}^{-}$of $50 \mathrm{ppb}$ before significant breakthrough of perchlorate occurred. In contrast, the A-530E resin could only treat $37000 \mathrm{BV}$ of contaminated groundwater with an influent $\mathrm{ClO}_{4}{ }^{-}$of $860 \mathrm{ppb}$ (Figure 5S of $\mathrm{SI}$ ) at a field site located in Rancho Cordova (CA) before significant breakthrough. ${ }^{31}$ Note that the concentrations of $\mathrm{SO}_{4}{ }^{2-}(15 \mathrm{mg} / \mathrm{L})$ and $\mathrm{NO}_{3}{ }^{-}(10 \mathrm{mg} / \mathrm{L})$ in the groundwater at the Rancho Cordova field site are significantly lower than those in the Redlands makeup groundwater (Table 1). Thus, we attribute the decrease in the OC of the A-530E resin at the Rancho Cordova site to its limited strong-base exchange capacity, which is equal to $0.6 \mathrm{eq} / \mathrm{L}$ (Table 2). A recent report by United States Government Accountability Office lists a large number of untreated groundwater sites with $\mathrm{ClO}_{4}{ }^{-}$concentrations ranging from 100 to $1000 \mathrm{ppb}^{32}$ Thus, perchlorateselective resins with high exchange capacity could expand the applicability of IX to the treatment of groundwater with influent $\mathrm{ClO}_{4}{ }^{-}$concentration higher than $500 \mathrm{ppb}$. Table 5

Table 5. Extrapolated Operational Capacities for the QPEI-4 and A-530E Resins in Redland Makeup Groundwater With Effluent $\mathrm{ClO}_{4}^{-}$Concentrations of $860 \mathrm{ppb}^{a}$

$\begin{array}{cccc}\text { resin } & \begin{array}{c}{ }^{b} \mathrm{OC}_{\text {measured }}\left(C_{0}^{\text {perc }}=\right. \\ 10 \mathrm{mg} / \mathrm{L})\end{array} & \begin{array}{c}{ }^{c} \mathrm{OC}_{\text {extrapolated }}\left(C_{0}^{\text {perc }}=\right. \\ 860 \mathrm{ppb})\end{array} & \begin{array}{c}\mathrm{OC}_{\text {measured }} C_{0}^{\text {perc }} \\ 860 \mathrm{ppb})\end{array} \\ \text { QPEI-4 } & 7558 & 87884 & { }^{d} \mathrm{NA} \\ \mathrm{A}-530 \mathrm{E} & 3200 & 37209 & { }^{e} 37000\end{array}$

${ }^{a_{T}}$ The concentration range for linear perchlorate sorption onto the QPEI-4 and A-530E Resins extends from $0.5 \mathrm{ppm}$ to $10 \mathrm{ppm}$ (Figure 4). ${ }^{b} \mathrm{OC}_{\text {measured }}$ : Measured operational capacity from column experiments (Figure 6). To reduce the duration of the column experiments, the initial concentration of perchlorate $\left(\mathrm{C}_{0}^{\text {perc }}\right)$ was set at $10 \mathrm{ppm}$. ${ }^{c} \mathrm{OC}_{\text {extrapolated }}$ : Extrapolated operational capacity for an initial concentration of perchlorate $\left(\mathrm{C}_{0}^{\text {perc }}\right)$ of $860 \mathrm{ppb} .{ }^{d} \mathrm{NA}$, not available ${ }^{e} \mathrm{OC}_{\text {measured }}$ : Estimated operational capacity from a field demonstration of perchlorate extraction conducted at an Aerojet field site located in Rancho Cordova (CA) (Figure 5S of the SI and ref 31). The concentration of sulfate $\left[\mathrm{SO}_{4}{ }^{2-}\right](15 \mathrm{mg} / \mathrm{L})$ in the groundwater field site is much lower than that in the Redlands makeup groundwater, which is equal to $49 \mathrm{mg} / \mathrm{L}$ (Table 1). Similarly, the concentration of nitrate $\left[\mathrm{NO}_{3}^{-}\right](10 \mathrm{mg} / \mathrm{L})$ is also significantly lower to that in the Redlands makeup groundwater, which is equal to $31 \mathrm{mg} / \mathrm{L}$ (Table 1).

shows the extrapolated operational capacity (OC) for the QPEI-4 and A-530E resins in Redland makeup groundwater with initial $\mathrm{ClO}_{4}{ }^{-}$concentration of $860 \mathrm{ppb}$. Note that both resins exhibit linear sorption isotherms in Redlands makeup groundwater with initial $\mathrm{ClO}_{4}{ }^{-}$concentrations ranging from 0.5 to $10 \mathrm{mg} / \mathrm{L}$ (Figure 4). Because the $K_{\mathrm{d}}$ values of the QPEI-4 and $\mathrm{A}-530 \mathrm{E}$ resins are constant in this concentration range (Figure 4), we assume that their column operational capacities for $\mathrm{ClO}_{4}^{-}$are controlled by their exchange capacities (Table 2). Based on this assumption, we express the operational capacity ([OC $]_{\mathrm{Xpm}}^{\mathrm{ClO} 4}$ ) of a QPEI-4/A-530E resin in Redlands makeup groundwater with an effluent $\mathrm{ClO}_{4}{ }^{-}$concentration equal to $X$ (ppm) [with $0.5 \mathrm{ppm} \leq X \leq 10 \mathrm{ppm}$ ] as follows:

$$
[\mathrm{OC}]_{\mathrm{Xpp}}^{\mathrm{ClO} 4}=\left(\frac{10}{X}\right)[\mathrm{OC}]_{10 \mathrm{ppm}}^{\mathrm{ClO} 4}
$$

where $[\mathrm{OC}]_{10 \mathrm{ppm}}^{\mathrm{ClO} 4}$ is the resin operational capacity in Redlands makeup groundwater with an effluent $\mathrm{ClO}_{4}{ }^{-}$concentration equal to $10 \mathrm{ppm}$ (Table 4 and Figure 6). To validate our extrapolation methodology, we subsequently used eq 5 to estimate the $\mathrm{OC}$ of the A-530E resin in Redlands groundwater with an effluent $\mathrm{ClO}_{4}^{-}$concentration of $860 \mathrm{ppb}$. Table 5 shows the estimated OC for the A-530E resin (37209 BV) in Redlands groundwater is very close to its measured OC (37000 $\mathrm{BV})$ in the groundwater from the Rancho Cordova site. ${ }^{31}$ Recall that the groundwater at the Rancho Cordova site has an influent $\mathrm{ClO}_{4}{ }^{-}$concentration of $860 \mathrm{ppb}$ with low concentrations of concentrations of sulfate $(15 \mathrm{mg} / \mathrm{L})$ and nitrate $(10$ $\mathrm{mg} / \mathrm{L}){ }^{31}$ Table 5 shows that the estimated OC for the QPEI-4 resin $(75580 \mathrm{BV})$ is 2.36 times larger than that of the $\mathrm{A}-530 \mathrm{E}$ resin $(37209 \mathrm{BV})$ in the Redlands makeup groundwater with influent $\mathrm{ClO}_{4}{ }^{-}$concentrations of $860 \mathrm{ppb}$. Thus, the overall results of our initial studies suggest that branched PEI beads provide versatile and promising building blocks for the preparation of perchlorate-selective resins (PSRs) with high exchange and operational capacities. Additional investigations are being conducted to optimize the physical properties (e.g., mechanical strength) and performance (e.g., selectivity and capacity) of our new PSRs for the treatment of drinking groundwater sources contaminated by higher concentrations of perchlorate $^{32}$ (e.g., 500-1000 ppb).

\section{ASSOCIATED CONTENT}

\section{Supporting Information}

Supporting information contains additional material as noted in the text. This material is available free of charge via the Internet at http://pubs.acs.org.

\section{AUTHOR INFORMATION}

\section{Corresponding Author}

*Phone: 626395 8133; e-mail: mdiallo@kaist.ac.kr or Diallo@ wag.caltech.edu.

\section{Notes}

The authors declare the following competing financial interest(s): Prof. Mamadou S. Diallo is the co-founder of a start-up company (AquaNano, LLC). This company is scaling up and commercializing a new generation of high performance media using branched macromolecules as building blocks..

\section{ACKNOWLEDGMENTS}

This research was carried out at the California Institute of Technology and AquaNano, LLC. Selected materials characterization studies (FT-IR and SEM) were carried out at the Korea Advanced Institute of Science and Technology (KAIST). Funding for this research was provided by the U.S National Science Foundation (NSF) [CBET Award 0506951]. M. S. Diallo and D. P. Chen were supported by the KAIST EEWS Initiative (NT080607C0209721). W. A. Goddard III was supported partially by the KAIST World Class University (WCU) program (NRF-31-2008-000-10055).

\section{REFERENCES}

(1) Hogue, C. Rocket-fueled river. Chem. \& Eng. News. 2003, 81, 37-46.

(2) Pontius, F. W.; Damian, P. Eaton, A. D. Regulating perchlorate in drinking water. In Perchlorate in the Environment; Urbansky, T. E., Ed.; Kluver Academic: New York, 2000.

(3) Mosier-Boss, P. A. Recent developments in perchlorate detection. In Perchlorate Environmental Occurrence, Interactions and Treatment; Gu, B. Coates, J. D., Eds.; Springer: New York, 2006. 
(4) California Office of Environmental Health Hazard Assessment. http://www.oehha.ca.gov/water/phg/010711perchlorate.html (accessed) 7 January 2011).

(5) Zhou, P., Brown, G. M. Gu, B. Membranes and other treatment technologies-pros and cons. In Perchlorate Environmental Occurrence, Interactions and Treatment; Gu, B., Coates, J. D., Eds.; Springer: New York, 2006.

(6) $\mathrm{Gu}, \mathrm{B} . \mathrm{H}$. Brown, G. M. Recent advances in ion exchange for perchlorate, treatment, recovery and destruction. In Perchlorate Environmental Occurrence, Interactions and Treatment; Gu, B. Coates, J. D., Eds.; Springer: New York, 2006.

(7) Tripp, A. R; Clifford, D. A. Ion exchange for the remediation of perchlorate-contaminated drinking water. J. Am. Water Works Assoc. 2006, 98, 105-114.

(8) Lehman, S. G.; Badruzzaman, M.; Adham, S.; Roberts, D. J.; Clifford, D. A. Perchlorate and nitrate treatment by ion exchange integrated with biological brine treatment. Water. Res. 2008, 42, 969976.

(9) Helfferich, F. Ion Exchange; McGraw-Hill Series in Advanced Chemistry: New York, 1962.

(10) Harland, C. E. Ion Exchange: Theory and Practice; The Royal Society of Chemistry: Cambridge, 1994.

(11) Sherrington, D. C. Preparation, structure and morphology of polymer supports. Chem. Commun. 1998, 2275-2286.

(12) Purolite A530E Macroporous strong base anion exchange resin. http://www.purolite.com/default.aspx?RelID=606288\&ProductID= 333 (accessed).

(13) Hagge, W.; Naumann, G.; Leverkusen;; O;, S. Polyethylene Imine Anion-Exchange Resins of Sponge-like Structure. US Patent 3,210,299. Patented October 5, 1965.

(14) Rivas, B. L.; Maturana, H. A.; Catalán, R. E.; Perich, I. M. Branched and linear polyethyleneimine supports for resins with retention properties for copper and uranium. VII. J. Appl. Polym. Sci. 1989, 38 (5), 801-807.

(15) Rivas, B. L.; Geckeler, K. E. Synthesis and metal complexation of poly(ethyleneimine) and derivatives. In Polymer Synthesis Oxidation Processes; Springer: Berlin/Heidelberg, 1992; Vol. 102.

(16) Shepherd, E. J.; Kitchener, J. A. 15. Studies of a cross-linked poly(ethyleneimine) ion-exchange resin. J. Chem. Soc. 1957, 86-92.

(17) Rademann, J.; Barth, M. ULTRA Loaded resins based on the cross-linking of linear Poly(ethyleneimine). Improving the atom economy of polymer-supported chemistry. Angew. Chem., Int. Ed. 2002, 41, 2975-2978.

(18) Barth, M.; Fischer, R.; Brock, R.; Rademann, J. Reversible crosslinking of hyperbranched polymers: A strategy for the combinatorial decoration of multivalent scaffolds. Angew. Chem., Int. Ed. 2005, 44, $1560-1563$.

(19) Roice, M.; Christensen, S. F.; Meldal, M. ULTRAMINE: a highcapacity Polyethylene-Imine-based polymer and its application as a scavenger resin. Chem.-Eur. J. 2004, 10, 4407-4415.

(20) Mishra, H.; Yu, C.; Chen, D. P.; Dalleska, N. F.; Hoffmann, M. R.; Goddard, W. A., III; Diallo, M. S. Branched polymeric media: boron-chelating resins from hyperbranched polyethyleneimine. Environ. Sci. Technol. 2012, 46, 8998-9004.

(21) ASTM D2187 - 94(2009): Standard Test Methods for Physical and Chemical Properties of Particulate Ion-Exchange Resins, 2009. http://www.madcad.com/store/subscription/ASTM-D2187-94Reapproved2009/ (accessed).

(22) Gu, B. H.; Brown, G. M., Alexandratos, S. D., Ober, R. Patel, V. Selective anion exchange resins for the removal of perchlorate $\left(\mathrm{ClO}_{4}{ }^{-}\right)$ from groundwater. Oak Ridge National Laboratory Report ORNL/ TM-13753, 1999.

(23) Clifford, D.; Sorg, T. J.; and Ghurye, G. L.. Ion Exchange and Adsorption of Inorganic Contaminants. In Water Quality and Treatment: A Handbook on Drinking Water; Edzwald, J. K., Ed.; American Water Works Association: Denver, 2011.

(24) Frechet, J. M. J., Boz, E., Chi, Y., Diallo, M. S. Extraction of anions from solutions and mixtures using hyperbranched macro- molecules. U.S. Patent Application. Pub No. US 2009/0181257 A1. Publication Date: July 22, 2010.

(25) Diallo, M. S., Yu, C. J. Soluble anion exchangers from hyperbranched macromolecules. U.S. Patent Application. Pub No. US 2011/0315636 A1. Publication Date: December 29, 2011.

(26) Arshady, R. Suspension, emulsion and dispersion polymerization: a methodological survey. Colloid Polym. Sci. 1992, 270, 717732.

(27) Diallo, M. S.; Falconer, K.; Johnson, J. H. Dendritic anion hosts: Perchlorate uptake by G5- $\mathrm{NH}_{2}$ Poly(propyleneimine) dendrimer in water and model electrolyte solutions. Environ. Sci. Technol. 2007, 41, $6521-6527$.

(28) Xiong, D.; Zhao; Harper, W. F. Sorption and desorption of perchlorate with various classes of ion exchangers: A comparative study. Ind. Eng. Chem. Res. 2007, 46, 9213-9222.

(29) Clifford, D.; Weber, W. J., Jr The Determinants of divalent/ monovalent selectivity in anion exchangers. React. Polym. 1983, 1, 7789.

(30) Gu.; B. Brown, G. Efficient treatment of perchlorate $\left(\mathrm{ClO}_{4}{ }^{-}\right)$contaminated groundwater by bifunctional anion exchange resins. In Perchlorate in the Environment; Urbansky, T. E., Ed.; Kluver Academic: New York, 2000; pp 165-176.

(31) Gu., B.; Brown, G.; Chiang, C.-C. Treatment of perchloratecontaminated groundwater using highly selective, regenerable ionexchange technologies. Environ. Sci. Technol. 2007, 41, 6277-6282.

(32) United States Government Accountability Office. Perchlorate: Occurrence Is Widespread but at Varying Levels; Federal Agencies Have Taken Some Actions to Respond to and Lessen Releases; United States Government Accountability Office: Washington, DC, 2010 